\title{
Climate Change Scenarios of Precipitation Extremes in the Carpathian Region Based on an Ensemble of Regional Climate Models
}

\author{
Ladislav Gaál, ${ }^{1,2}$ Romana Beranová, ${ }^{1}$ Kamila Hlavčová, ${ }^{2}$ and Jan Kyselý ${ }^{1,3}$ \\ ${ }^{1}$ Institute of Atmospheric Physics, Academy of Sciences of the Czech Republic, Boční II/1401, 14131 Prague 4, Czech Republic \\ ${ }^{2}$ Department of Land and Water Resources Management, Faculty of Civil Engineering, Slovak University of Technology, \\ Radlinského 11, 81368 Bratislava, Slovakia \\ ${ }^{3}$ Global Change Research Centre, Academy of Sciences of the Czech Republic, Bèlidla 986/4a, 60300 Brno, Czech Republic
}

Correspondence should be addressed to Ladislav Gaál; ladislav.gaal@stuba.sk

Received 24 April 2014; Revised 4 July 2014; Accepted 5 July 2014; Published 16 September 2014

Academic Editor: Yijun He

Copyright (C) 2014 Ladislav Gaál et al. This is an open access article distributed under the Creative Commons Attribution License, which permits unrestricted use, distribution, and reproduction in any medium, provided the original work is properly cited.

\begin{abstract}
The study examines projected changes in precipitation extremes, aggregated on several time scales ( 1 hour, 1 day, and 5 days), in simulations of 12 regional climate models (RCMs) with high spatial resolution $(\sim 25 \mathrm{~km})$. The study area is the Carpathian Basin (Central and Southeastern Europe) which has a complex topography and encompasses the whole territory of Slovakia and Hungary as well as major parts of Romania and western Ukraine. We focus on changes in mean seasonal maxima and high quantiles (50-year return values) projected for the late 21st century (time slice 2070-2099) in comparison to the control period (time slice 1961-1990), for summer and winter. The 50-year return values are estimated by means of a regional frequency analysis based on the region-ofinfluence method, which reduces random variability and leads to more reliable estimates of high quantiles. In winter, all examined characteristics of precipitation (seasonal totals, mean seasonal maxima, and 50-year return values for both short-term and multiday aggregations) show similar patterns of projected increases for the late 21 st century. In summer, by contrast, drying is projected for seasonal totals in all RCMs while increases clearly prevail for the 50-year return values. The projected increases are larger for short-term (hourly) extremes that are more directly related to convective activity than multiday extremes. This suggests that the probability of occurrence of flash floods may increase more than that of large-scale floods in a warmer climate. The within-ensemble variability (and associated uncertainty) is, nevertheless, much larger in summer than in winter.
\end{abstract}

\section{Introduction}

Heavy precipitation events are of great importance since they cause soil erosion, landslides, and floods. Precipitation extremes may result in excessive damage and negative consequences for human society regardless of the time scale of the events; while heavy short-term precipitation, predominantly of a duration of a couple of hours and from localized convective systems, may be one of the triggering factors of flash floods (e.g., [1]), heavy precipitation events, usually of frontal or cyclonic origin [2] and of a duration of several days, may lead to devastating large-scale floods (e.g., [3]). In the last two decades, Central and Southeastern Europe were affected by a number of severe floods of both major types (see, e.g., [4,
Table 1] and the references therein). Very recently, in midMay 2014, parts of Southeastern Europe, mainly Serbia and Bosnia and Herzegovina, experienced the worst flooding over the last 120 years, with enormous damage to infrastructure, more than 60 victims, and hundreds of thousands people having been forced to leave their homes (http://en.wikipedia .org/wiki/2014_Southeast_Europe_floods). It is therefore of a particular interest how climate change will affect the hydrological cycle globally and how it will be manifested on a regional scale, in different regions of Europe. Warmer atmosphere has enhanced water holding capacity, and, therefore, it is expected on a theoretical basis that climate change may also increase severity and/or frequency of heavy precipitation events [5]. 
Climate change studies focusing on Central and Southeastern Europe generally agree that, by the end of the 21st century, the region will experience pronounced warming, however, with seasonal differences in magnitude $[6,7]$. While mean annual precipitation is not projected to change significantly, its intra-annual distribution will likely be affected considerably: overall drying is expected in the summer season, while richer precipitation conditions are projected for winter $[8,9]$.

Most climate models agree on more intense and more frequent precipitation extremes in a warmer climate in many regions of Europe (e.g., [10,11]). Nevertheless, climate change scenarios of heavy precipitation that focus on Central Europe [12-14] are less conclusive, pointing out the role of the area as a "transition zone" between Northern and Southern Europe and Western and Eastern Europe, respectively [15].

While there are a number of studies dealing with the future changes from 1-day to multiday heavy precipitation in Europe (e.g., [11, 15-17]), the issue of changes in precipitation extremes on a subdaily scale, relevant for flash floods, has still been unsatisfactorily explored. This may be due to the fact that short-term (hourly) precipitation amounts were made available only recently among the outputs of regional climate models (RCMs). On the basis of future projections of a single RCM (HIRHAM4), Larsen et al. [18] report an overall increasing tendency of heavy 1-hour precipitation, with larger increases in Northern and Central Europe compared to southern parts of the continent. Furthermore, most studies are consistent in projecting larger increases in hourly precipitation extremes than in extremes of daily or multiday precipitation [18-20]. Nevertheless, Hanel and Buishand [21] point out that convective processes may not be properly represented in some RCMs, and, therefore, hourly maxima may often be underestimated.

Possible future regime of heavy precipitation is very often examined by means of precipitation indices on the basis of recommendation of Frich et al. [22] (e.g., [6, 7, 23]). However, in these studies, statistics are usually estimated purely on the basis of grid box data samples. Even though these grid box statistics are often spatially smoothed, the results may still be affected by large sampling variability, which may question their reliability. The issue of reducing random spatial variability becomes particularly important towards tails of distributions of extremes (which are mainly relevant for impacts and/or engineering design) as well as with increasing spatial resolution of climate models.

As the present study aims at studying also such high quantiles of distributions of precipitation extremes (50-year return values), we adopt a regional frequency analysis for the estimation of parameters of the distributions of extremes, namely, the region-of-influence (ROI) method [24]. It pools regionally weighted information on precipitation extremes from a certain number of neighboring (similar) grid boxes (more details in Methods Section), which may also be viewed as a form of spatial smoothing of the grid box data. Due to the regional pooling, the estimates of high quantiles in each grid box become less influenced by random variations. Kyselý et al. [15] already adopted the ROI method for the analysis of
RCM outputs with respect to precipitation extremes in a part of Central Europe (the Czech Republic).

The current study sets focus on central to southeastern parts of Europe that were affected by several severe flood events recently (cf. [4, Table 1]), including the massive flooding in mid-May 2014 (see above). The target region seems to be overlooked among similar flood and/or heavy precipitation risk studies in Europe that have been mainly focused on the United Kingdom, Western Europe, Central Europe, or the Mediterranean.

In addition to daily and multiday amounts, we examine also projected changes in extremes of very short-term (1hour) duration in summer which are usually related to convective processes and may lead to extreme flash floods. In order to reduce uncertainties stemming from the use of a single RCM, outputs of an ensemble of high-resolution RCM simulations are examined.

\section{Data and Methods}

2.1. Data. We examine outputs of $12 \mathrm{RCM}$ simulations from the EU-FP6 project ENSEMBLES [25]. The ensemble consists of 6 RCMs driven by 4 different GCMs. An overview of the RCM simulations is given in Table 1; further details on the particular RCMs may be found in the references given therein. The RCM simulations cover the whole European area. Data in two time slices are examined: 1961-1990 (representing control climate) and 2070-2099 (climate change scenario under the SRES A1B emission scenario [5]). Driving GCMs for the RCM simulations (control ones as well as scenarios) are the Max Planck Institute ECHAM5 model [26], the Bergen Climate Model BCM [27], Arpege developed in Météo-France [28], and Hadley Centre coupled model HadCM3 [29].

All RCMs have high spatial resolution that corresponds to a grid size of approximately $25 \mathrm{~km}$. The study area is the Carpathian Basin (delimited by grid boxes between 17.0$28.0^{\circ} \mathrm{E}$ and $44.5-50.5^{\circ} \mathrm{N}$ ), which covers the whole territory of Slovakia and Hungary, a major part of Romania, and minor parts of their neighboring countries (Austria, the Czech Republic, Poland, Ukraine, Moldova, Serbia, Bosnia and Herzegovina, and Croatia; Figure 1). The region consists of 926 grid boxes, representing an area of $\sim 580$ thousand $\mathrm{km}^{2}$.

Abilities of the RCMs to reproduce observed heavy precipitation patterns over Europe and their applicability into constructing climate change scenarios have been assessed in some previous studies [10, 21, 30-32]. Many observed characteristics of extremes are well simulated by the RCMs, although differences in the models' performance exist [25]. The RCMs are also able to reproduce main features of atmospheric circulation and its links to precipitation in Central Europe [33].

\subsection{Climate Change Scenarios and Precipitation Characteris-} tics. Climate change scenarios are evaluated for the late 21st century (2070-2099) with respect to the control period (19611990). The only exception is the CLM model in which, due to errors and missing data, the period 2091-2099 had to be 

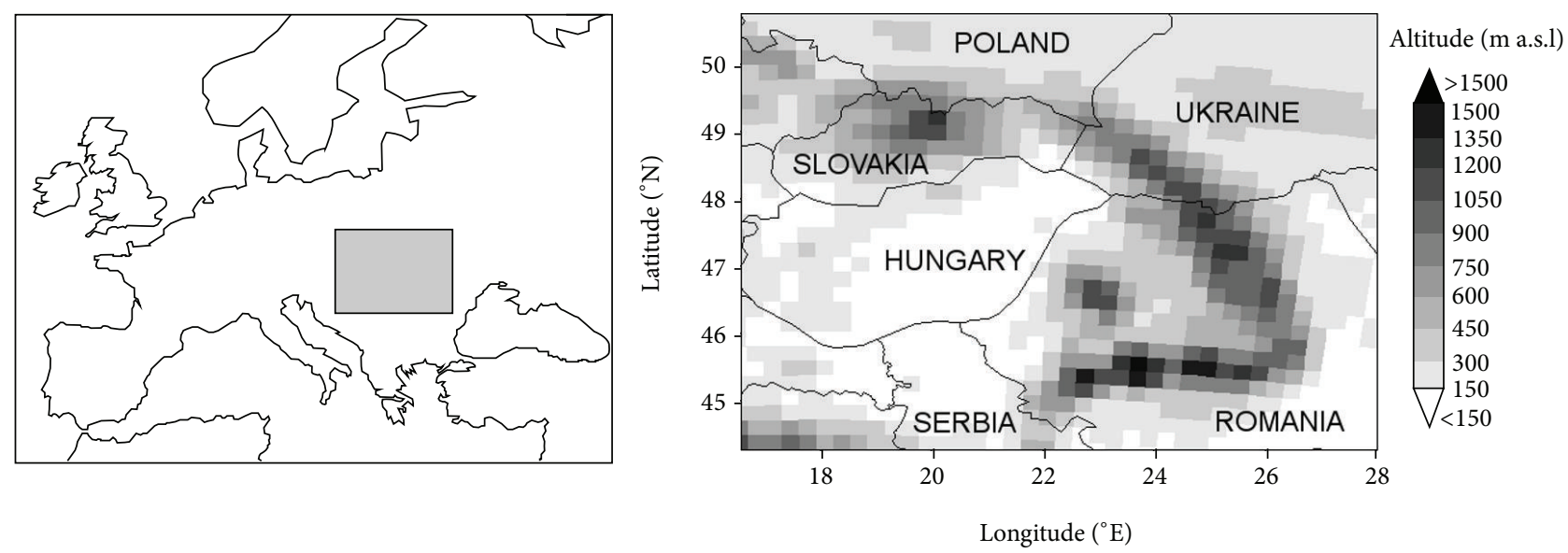

FIgURE 1: Carpathian Basin: the area under study $\left(17-28^{\circ} \mathrm{E}, 44.5-50.5^{\circ} \mathrm{N}\right)$. Orography is taken from model RCA3.

TABLE 1: Regional climate model simulations used and their basic characteristics.

\begin{tabular}{lccc}
\hline Institute & RCM & Driving GCM & Description in \\
\hline $\begin{array}{l}\text { SMHI, Rossby } \\
\text { Centre }\end{array}$ & RCA & $\begin{array}{c}\text { ECHAM5 } \\
\text { HadCM3Q3 } \\
\text { HadCM3Q16 }\end{array}$ & {$[62]$} \\
\hline $\begin{array}{l}\text { MetOffice, } \\
\text { Hadley Centre }\end{array}$ & HadRM3 & $\begin{array}{c}\text { HadCM3Q0 } \\
\text { HadCM3Q3 }\end{array}$ & {$[63]$} \\
\hline DMI & HadCM3Q16 & \\
\hline KNMI & HIRHAM & ARPEGE & {$[64]$} \\
\hline MPI & ECHAM5 & {$[65]$} \\
\hline ETHZ & REMO & ECHAM5 & {$[66]$} \\
\hline
\end{tabular}

omitted; thus only the remaining 21-year period was taken for the future scenario. In all computations, the projected climate change is expressed as the percent change relative to the control period. All scenarios are taken from transient runs under the SRES A1B emission scenario [5].

We focus on precipitation extremes that occur on different time scales:

(i) hourly precipitation $(1 \mathrm{~h})$ in summer, extremes of which are usually associated with severe convective phenomena (cf. [34]) and may lead to flash floods,

(ii) daily precipitation ( $1 \mathrm{~d}$ ) in winter, examined as a counterpart to $1 \mathrm{~h}$ precipitation in summer to represent short-term extremes,

(iii) 5-day precipitation (5 d) in both summer and winter, which represents multiday extremes that are often considered proxies for large-scale floods (cf. [17, 3539]).

The seasons are defined in a standard way as JJA (summer) and DJF (winter). The choice of the short-term precipitation duration differs between summer and winter due to climatology of precipitation in the studied region: extremes are often of convective origin in summer and duration of these rainfall events is typically up to a few hours, while the proportion of convective precipitation in winter is negligible in Central Europe [40] and winter extremes are usually associated with longer-lasting stratiform frontal precipitation.

Projected changes in mean seasonal maxima of the given characteristics and their 50 -year return values (estimated by the ROI method described in the following section) are examined. The 50-year return level is chosen to represent severe high-impact extremes, which cannot be reliably estimated from local (at-site) data, and the level is also related to the planning horizon for engineering system design, which is typically about $\sim 20-100$ years [41].

2.3. Methods. In a regional frequency analysis, data from different sites (grid boxes in our application) are pooled, in order to supplement the sample of extremes at the target grid box and to obtain more reliable estimates (e.g., [42]). The criterion of regional homogeneity, that is, that the samples at different sites (grid boxes) have the same distribution except for a scaling factor, is verified by statistical tests (e.g., [43]). In the present study, the test of Lu and Stedinger [44] is adopted.

The region-of-influence (ROI) approach is applied as a pooling scheme (note that the term "pooling" refers to a regional frequency analysis procedure that may result in a pooling group whose units are scattered in the geographical space but are close to each other in some attribute space [45]). The method was originally designed for flood frequency estimation [24, 46]. Later, Gaál et al. [47] and Gaál and Kyselý [48] extended its use to precipitation extremes, and, more specifically, the ROI method was adjusted to frequency estimation of precipitation extremes in a regular grid of RCMs [15]. Therefore, we confine the description of the methodology to its key features; more details can be found in [15]. Among advantages of the ROI method compared to regional frequency analysis based on fixed regions is that subjective decisions are reduced, and the method may easily be applied into large datasets (such as grids of RCMs). 
In the first step, a unique pooling group is identified for each target site using a dissimilarity measure based on geographical proximity between pairs of grid boxes. According to a simulation study [49], this measure outperforms others that involve also climatological characteristics in terms of root mean square error of estimated quantiles. Homogeneous pooling groups are identified in an automated way, according to the following algorithm. The homogeneity of the pooling group that consists of all $N_{\text {min }}$ grid boxes within the minimum radius $R_{\min }$ from the target grid box is tested. If the given pooling group is homogeneous, $N_{\text {min }}$ defines its size. Otherwise, the next closest grid box is added to the temporary pooling group, and the regional homogeneity is checked again. This procedure is repeated until either a homogeneous composition is obtained or the maximum radius $R_{\max }$ from the target grid box is reached. The latter case yields a failure of the build-up phase and the algorithm returns to its initial stage with $N_{\min }$. At this point, a similar procedure starts in an opposite way: grid boxes are step by step removed from the temporary pooling group, again until either a homogeneous composition of the pooling group is found or there are no more grid boxes to remove from the pooling group. In the latter case, the iterative procedure quits; the pooling group of the target grid box consists of nothing but itself, which corresponds to at-site frequency estimation.

Parameter $R_{\min }$, the minimum radius around the target grid box within which homogeneous pooling group is preferably looked for, is set to $100 \mathrm{~km}$. Considering that the grid box size is $\sim 25 \times 25 \mathrm{~km}$, the minimum size of the initial pooling group $N_{\min }$, corresponding to $R_{\min }$, is then 50 . The value of $N_{\text {min }}=50$ implies, given 30 years of data, 1500 station-years of data for each grid box, which is a sufficiently robust basis for the estimation of high quantiles. $R_{\max }$, the maximum radius distance, is set to $500 \mathrm{~km}$, which is compatible with the size of the region. Note that the algorithm of building homogeneous pooling groups is applied into the whole European grid, and the areal mask of the Carpathian Basin is adopted only after all computations were carried out. This step ensures that no boundary limitations appear since the target region is located sufficiently far from the edges of the European grid of the RCMs.

As soon as the composition of a particular pooling group is known, the regional information is transferred to the target grid box. At each grid box within the pooling group, sample L-moments are estimated. L-moments are statistical characteristics analogous to conventional (product) moments: they describe the scale and shape properties of a sample or a probability distribution (for the definition and a detailed description of L-moments, see, e.g., [42]). The L-moments at the target grid box are then obtained as the weighted regional (pooled) averages of the corresponding L-moments from the grid boxes of the pooling group, while the weights are proportional to the inverse of the distance between the individual grid boxes and the target one. Parameters of the generalized extreme value (GEV) distribution [50] of seasonal maxima are estimated, and quantiles corresponding to the 50-year return values are set. The procedure is carried out independently in each RCM, for each time slice and precipitation characteristic ( $1 \mathrm{~h}$ and $5 \mathrm{~d}$ maxima in summer;
$1 \mathrm{~d}$ and $5 \mathrm{~d}$ maxima in winter). Performance of the ROI method is evaluated in Results Section.

Uncertainty of the estimates (confidence intervals, CIs) can only be obtained in the regional frequency analysis using bootstrap resampling techniques [42]. However, due to a large number of grid boxes and high demands on computing time (the simulations would have to be carried out for each RCM, grid box, season, precipitation characteristic, and time slice separately), we confine to analytical formulae based on asymptotic approximations [51]. They are based on atsite data, so the width of the estimated CIs represents an upper limit for true CIs from the regional analysis and their application cannot falsely indicate statistical significance. Note also that the focus of the present study is on ensemble mean patterns and not results from individual RCMs.

The present study deals with a topic and methodology similar to [15], but there are important differences between the two papers in addition to different regions studied. While Kyselý et al. [15] worked with grid cells within the (small) target area only, which may have resulted in asymmetrical shape of pooling groups towards boundaries of the region, the regional estimates are carried out for the entire European grid in the present paper and the mask of the Carpathian region is adopted after all computations. This allows avoiding asymmetry in the shape of the pooling groups due to boundary limitations. Variables of interest also differ between the two studies; while Kyselý et al. [15] analyzed return values of daily precipitation only, a range of temporal aggregation scales of precipitation (from 1 hour to 5 days) is analyzed in the present paper.

\section{Results}

3.1. Performance of the Regional Frequency Analysis. The performance of the regional frequency estimation is evaluated through statistics of the size of the pooling groups (Table 2). If averaged over all RCMs and all combinations of seasons, precipitation aggregations and time slices (96 different datasets), the initial size of the pooling group with $N_{\text {min }}$ was found homogeneous in almost $3 / 4$ of the cases. The building (reducing) procedure of construction of homogeneous pooling groups ended successfully in 4\% (22\%) of the cases, while the at-site analysis is found to be the only acceptable model in a very small fraction of grid boxes $(\sim 1 \%)$. A higher percentage of single-site regions is identified for $1 \mathrm{~h}$ precipitation $(2.7 \%)$ compared to $1 \mathrm{~d}$ and $5 \mathrm{~d}$ precipitation $(\leq$ $0.5 \%$, Table 2 ), which is related to more random nature and higher variability in spatial fields of $1 \mathrm{~h}$ precipitation extremes. This can be explained in two ways: (i) the outlying values of the coefficient of variation and/or shape parameter at some grid boxes made the homogeneity testing impossible or (ii) the grid box represented an outlier for which no similar grid boxes could be found. However, the percentage of such cases is small, and standard at-site estimation is applied in those grid boxes.

If the evaluation is only constrained to "mountain" (higher-elevated) grid boxes with elevation exceeding $800 \mathrm{~m}$ a.s.l., we obtain slightly different results (Table 2), with (i) 
TABLE 2: Statistics of the size of the pooling groups, averaged across 12 RCMs and two time slices (1961-1990, 2070-2099). For the definition of "mountain" grid boxes, see text.

\begin{tabular}{|c|c|c|c|c|c|c|c|}
\hline & $\begin{array}{c}\text { Number of } \\
\text { datasets }\end{array}$ & $\begin{array}{l}\text { Mean number } \\
\text { of grid boxes }\end{array}$ & $\begin{array}{c}N=N_{\min } \\
(\%)\end{array}$ & $\begin{array}{c}N>N_{\min } \\
(\%)\end{array}$ & $\begin{array}{c}1<N<N_{\min } \\
(\%)\end{array}$ & $\begin{array}{c}N=1 \\
(\%)\end{array}$ & $\begin{array}{c}\text { Mean } \\
(N)\end{array}$ \\
\hline All & 96 & 926.0 & 73.5 & 4.0 & 21.5 & 1.0 & 48.6 \\
\hline All $1 \mathrm{~h}$ & 24 & 926.0 & 65.5 & 5.8 & 26.0 & 2.7 & 52.0 \\
\hline All 1d & 24 & 926.0 & 73.9 & 4.1 & 21.7 & 0.3 & 46.3 \\
\hline All $5 \mathrm{~d}$ & 48 & 926.0 & 77.3 & 3.1 & 19.1 & 0.5 & 48.1 \\
\hline Mountain & 96 & 88.8 & 51.2 & 5.0 & 41.5 & 2.3 & 44.8 \\
\hline Mountain $1 \mathrm{~h}$ & 24 & 88.8 & 49.8 & 7.5 & 38.1 & 4.6 & 59.7 \\
\hline Mountain 1d & 24 & 88.8 & 48.4 & 3.9 & 46.0 & 1.7 & 35.1 \\
\hline Mountain $5 \mathrm{~d}$ & 48 & 88.8 & 53.3 & 4.3 & 40.9 & 1.4 & 42.1 \\
\hline
\end{tabular}

lower percentage of grid boxes that are homogeneous at the initial size $N_{\text {min }}$, (ii) higher percentage of smaller pooling groups, and (iii) higher percentage of single-site regions. (Note that, as different RCMs use different orography, the number of "mountain" grid boxes in the studied area differs among the RCMs and ranges from 82 to 109.) However, even in such areas and for all aggregations including $1 \mathrm{~h}$ precipitation extremes, the percentage of grid boxes in which a local analysis had to be performed is less than $5 \%$.

3.2. Climate Change Scenarios of Precipitation Extremes. As already mentioned we focus on ensemble mean patterns and not results of individual RCMs. This is possible since the RCMs share almost identical grid. However, the spread of patterns as simulated by the RCMs and differences among the RCMs are important for characterizing and understanding uncertainty. An example of spatial patterns of the projected changes simulated by the RCMs is shown in Figure 2, while ensemble mean patterns across all 12 RCMs and the spread among the individual RCMs, characterized by the $75 \%$ and $25 \%$ quantiles of the distribution of projected changes of a given characteristic in each grid box, are shown in Figure 3.

The general structure of each figure composition in Figures 2 and 3 is similar. Each figure shows projected relative changes (in \%) of selected precipitation characteristics for the late 21st century (2070-2099) in comparison with the control period (1961-1990). Individual panels depict seasonal precipitation characteristics for winter (DJF, top) and summer (JJA, bottom), from left to right:

(i) mean seasonal precipitation,

(ii) mean seasonal maxima of 1-day (DJF) or 1-hour (JJA) precipitation,

(iii) mean seasonal maxima of 5-day precipitation,

(iv) 50-year return values of seasonal maxima of 1-day (DJF) or 1-hour (JJA) precipitation,

(v) 50-year return values of seasonal maxima of 5-day precipitation.

Table 3 summarizes the results for all RCMs in terms of the areal (grid box) averages of relative changes (in \%) for the whole target domain. Table 4 then shows a similar overview corresponding to Figure 3.

\subsection{Winter Season (DJF)}

Seasonal Precipitation. With the exception of the HIRHAM/ARPEGE model, all RCMs agree on increases in winter precipitation totals if averaged over the area (Table 3). Q75 and the ensemble mean are clearly positive (Figure 3 ), with an average of $25 \%$ and $17 \%$ over the study area, respectively (Table 4). Q25 is still positive on average (9\%); however, a minor meridional gradient can be seen in its spatial distribution (Figure 3), with slightly larger change to wetter conditions in the northern and central parts of the area compared to indifferent changes south of Hungary and from central Romania southward (Figure 3).

Mean Seasonal Maxima. A high degree of consistency among RCMs is also found in changes of the mean seasonal maxima in winter. All RCMs project increases, on average by about $10 \%$ for both precipitation durations (Table 3 ). The differences between RCMs are, rather surprisingly, somewhat smaller than those for seasonal precipitation. By contrast to seasonal means, larger areas with small or indifferent changes appear for both precipitation durations, particularly in the map of the lower ensemble quantile Q25 (Figure 3).

Precipitation Extremes. Projected changes in the 50-year return values are in agreement with the changes in seasonal precipitation totals and seasonal maxima: all RCMs project considerable increases for both durations. The spatially averaged increases exceed $20 \%$ in most RCMs and reach $45 \%$ for HadRM3 and 1-day maxima (Table 3, Figure 2). There are no important differences between the two durations when examining the spatial distribution of the statistics in ensemble maps (Figure 3) and their spatial averages (Table 4). The main features are

(i) uniformly positive changes for Q75 in the whole target area (around 35\%);

(ii) uniformly positive changes for ensemble mean (almost 25\%), with large degree of consistency among the models in the sign of change, indicated by the density of the "+" signs (Figure 3);

(iii) prevalence of areas with positive changes also for Q25 (nevertheless, smaller areas with indifferent or even slightly negative changes appear, mostly in Romania; they, however, do not form contiguous units). 

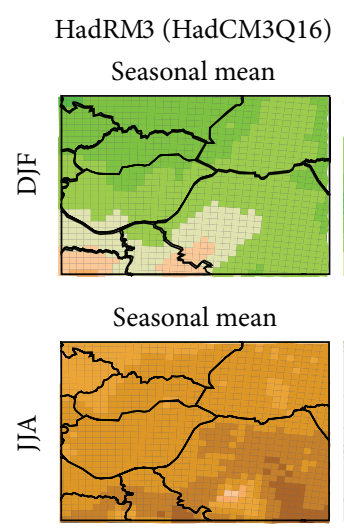

HIRHAM (ARPEGE)

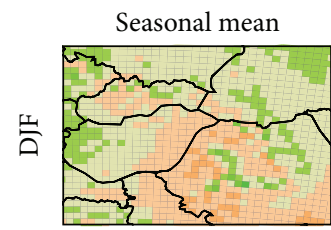

Seasonal mean

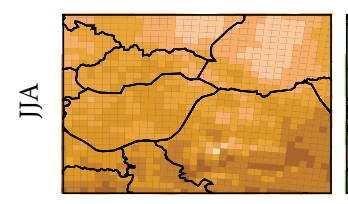

HIRHAM (ECHAM5)

Seasonal mean
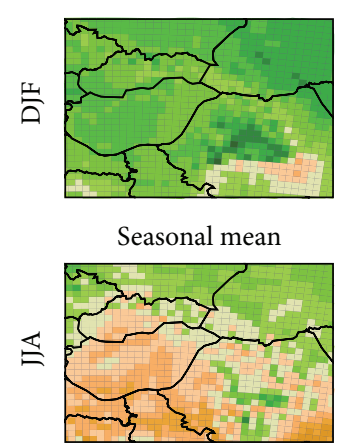

Seasonal maxima

$1 \mathrm{~d}$

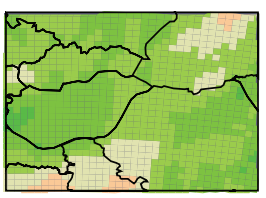

$1 \mathrm{~h}$

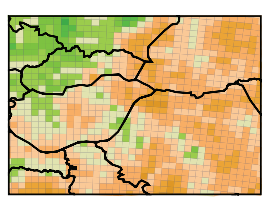

$5 \mathrm{~d}$

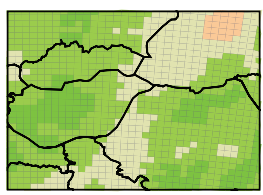

$5 \mathrm{~d}$

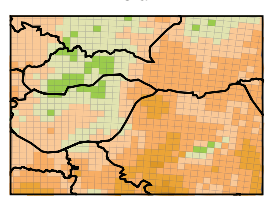

150-year return values

$1 \mathrm{~d}$

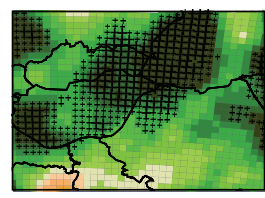

$1 \mathrm{~h}$

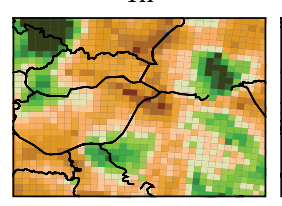

$5 d$

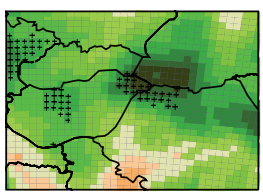

$5 \mathrm{~d}$

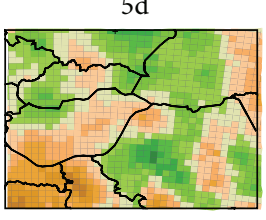

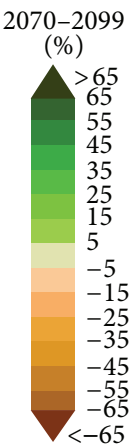

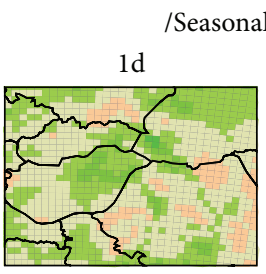

$1 \mathrm{~h}$

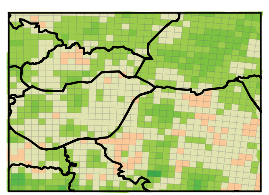

$5 d$

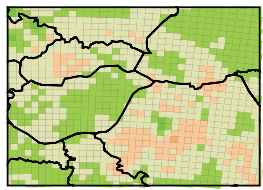

$5 \mathrm{~d}$

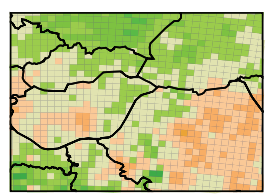

/Seasonal maxima

$1 \mathrm{~d}$

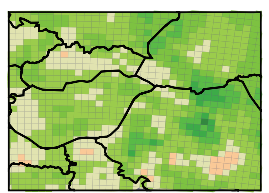

$1 \mathrm{~h}$

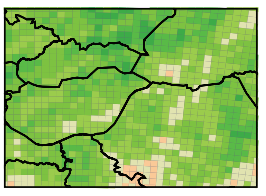

$5 \mathrm{~d}$

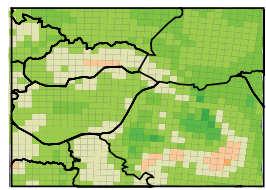

$5 d$

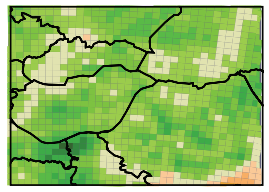

150-year return values

$1 \mathrm{~d}$

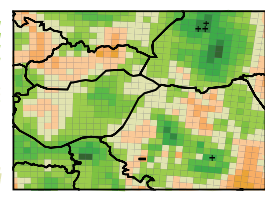

$1 \mathrm{~h}$

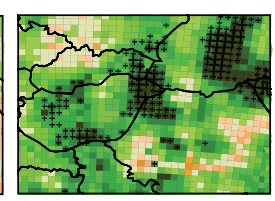

150-year return values

$1 d$

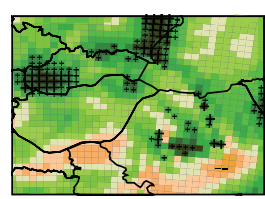

$1 \mathrm{~h}$

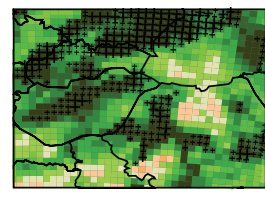

$5 d$

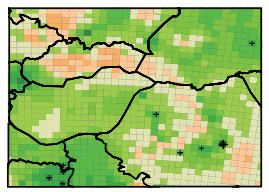

$5 \mathrm{~d}$

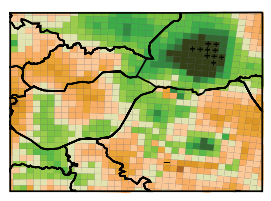

$5 d$

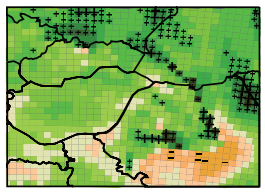

$5 d$

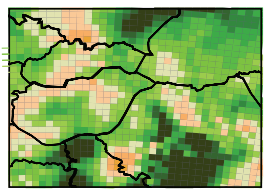

2070-2099

(\%)

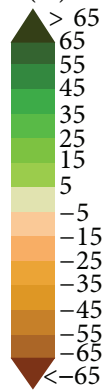

FIGURE 2: Projected relative changes (in \%) for the late 21st century (2070-2099) in comparison with the control period (1961-1990) of mean seasonal precipitation, mean seasonal maxima, and 50-year return values of 1-hour/1-day and 5-day precipitation assessed by the pooling (ROI) approach, for 3 selected RCMs. Large (small) "+/-" signs denote grid boxes where the estimated 90\% (80\%) CIs of the 50-year return values do not overlap. For further details and explanation, see text.

\subsection{Summer Season (JJA)}

Seasonal Precipitation. Summer precipitation totals are projected to decrease by the end of the 21st century in all RCMs. The spatially averaged reduction exceeds $20 \%$ in most models and reaches $40 \%$ in HadRM3 (Table 3, Figure 2). Only two RCM simulations project moderate decreases (below $10 \%$ ), including HIRHAM driven by ECHAM5 (Figure 2). This fact is also reflected on the maps of ensemble statistics (Figure 3): Q25 and the ensemble mean are clearly negative in the entire target area (on average $-36 \%$ and $-23 \%$, resp., Table 4 ), while in the spatial distribution of Q75, a slight meridional gradient is observed, with less dry conditions in the northern regions than in the south (Figure 3).

Mean Seasonal Maxima. For mean seasonal maxima in summer, a high degree of inconsistency can be noticed among the RCMs (manifested also in Figure 2), since the regional averages of the projected changes vary in a wide range around zero (both increases and decreases of the magnitude of 10$15 \%$ appear; Table 3). This is also reflected on the maps of the ensemble statistics: for both durations, negative (positive) changes dominate for Q25 (Q75), while grid boxes with indifferent changes prevail on the map of the ensemble mean 
Q75/

Seasonal mean

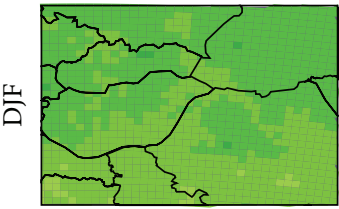

Seasonal mean

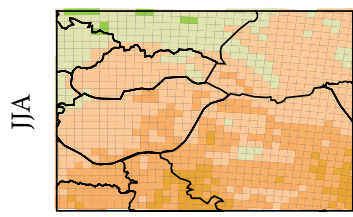

Ens. mean
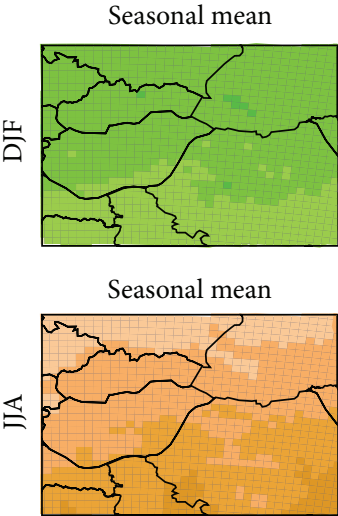

Q25/

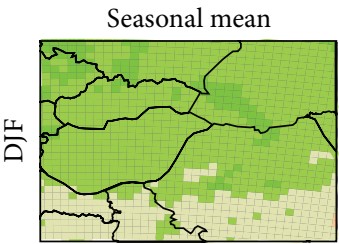

Seasonal mean

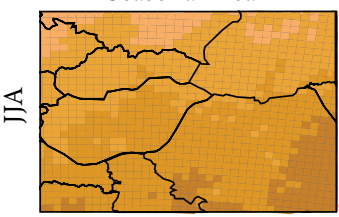

Q75/ seasonal maxima

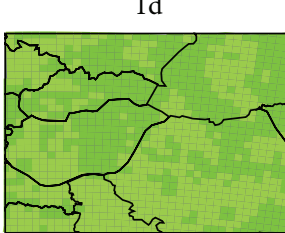

$1 \mathrm{~h}$

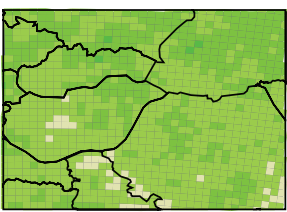

Ens. mean/ seasonal maxima

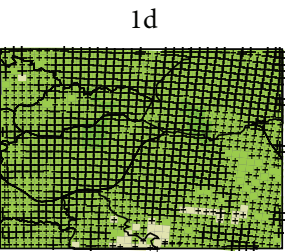

$1 \mathrm{~h}$

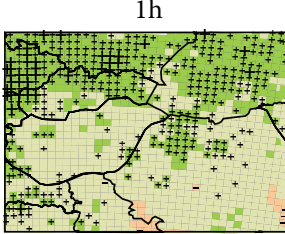

Q25/ seasonal maxima

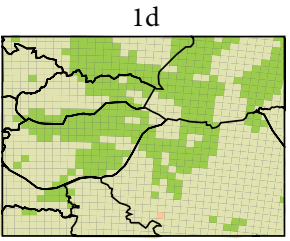

$1 \mathrm{~h}$

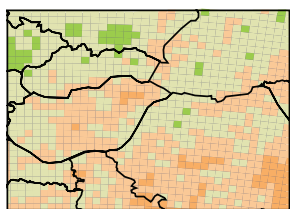

$5 \mathrm{~d}$

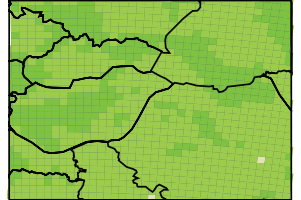

$5 d$

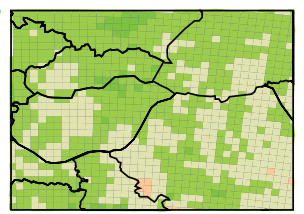

$5 \mathrm{~d}$
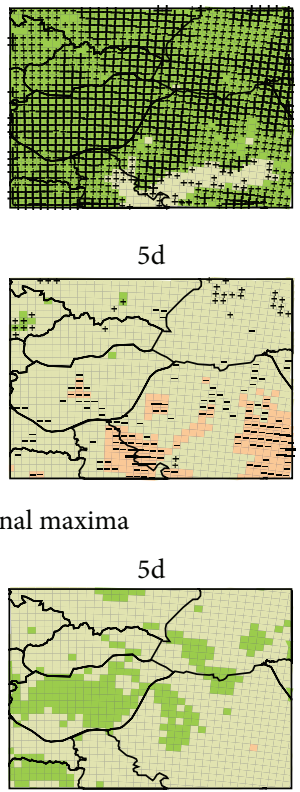

$5 \mathrm{~d}$

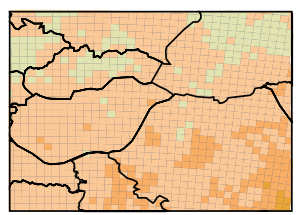

Q75/ 50-year return values

$1 \mathrm{~d}$

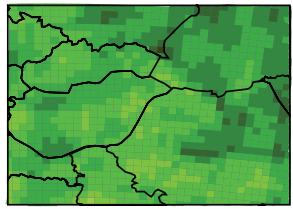

$1 \mathrm{~h}$
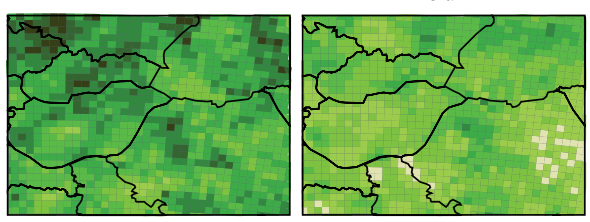

Ens. mean/ 50-year return values

$1 \mathrm{~d}$

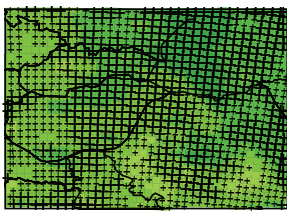

$1 \mathrm{~h}$

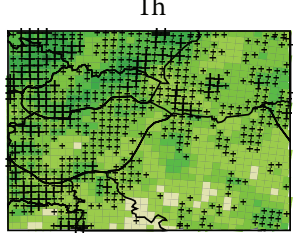

$5 d$

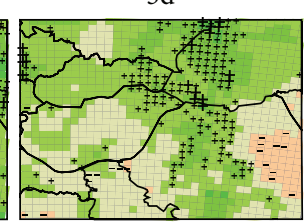

(\%)

(\%)
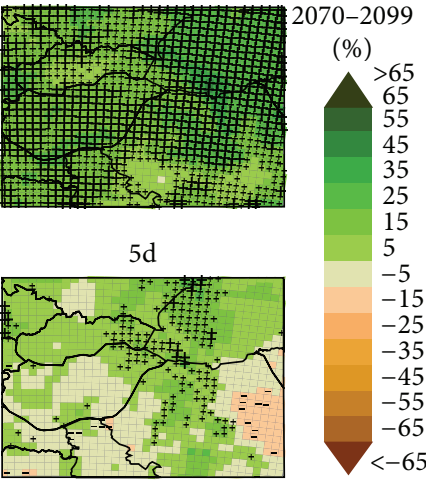

Q25/ 50-year return values

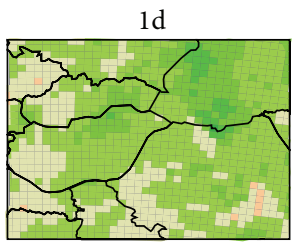

$1 \mathrm{~h}$

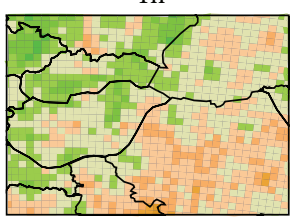

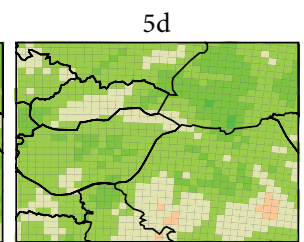

2070-2099

(\%)

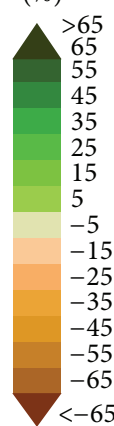

Figure 3: Ensemble mean and ensemble quantiles (Q25 and Q75) of the projected relative changes (in \%) for the late 21st century (20702099) in comparison with the control period (1961-1990) of mean seasonal precipitation, mean seasonal maxima of 1-hour/1-day and 5-day precipitation, and 50-year return values of 1-hour/1-day and 5-day precipitation assessed by the pooling (ROI) approach. Large (small) "+/-" signs indicate grid boxes where at least 10 (8) of the 12 RCMs agree on the sign of change for the given precipitation characteristic. For further details and explanation, see text.

(Figure 3). Nevertheless, all the RCMs indicate drier future conditions for multiday ( $5 \mathrm{~d}$ ) than short-term ( $1 \mathrm{~h}$ ) maxima, for which increases tend to prevail (Table 3 ).

Precipitation Extremes. In contrast to the overall drying in summer, high quantiles (50-yr return values) in this season are generally projected to increase. Nevertheless, Table 3 indicates a lower consistency among the individual RCMs compared to winter. Some RCMs project enhanced increases (even by $>30 \%$ on average for $1 \mathrm{~h}$ precipitation and $>20 \%$ for $5 \mathrm{~d}$ precipitation), but, in 2 (3) RCMs for the $1 \mathrm{~h}(5 \mathrm{~d})$ extremes, the spatial averages of the projected changes are 
TABLE 3: Average relative changes (in \%) of mean seasonal precipitation totals, mean seasonal maxima, and 50-year return values of 1-hour/1day and 5-day precipitation amounts in the Carpathian Basin (lon. 17-28 E, lat. 44.5-50.5 N) between 2070-2099 and 1961-1990.

\begin{tabular}{|c|c|c|c|c|c|c|}
\hline \multicolumn{7}{|c|}{ DJF } \\
\hline $\mathrm{RCM}$ & Driving GCM & $\begin{array}{l}\text { Mean seasonal } \\
\text { precipitation }\end{array}$ & $\begin{array}{c}\text { Mean seasonal } \\
\text { maxima of } 1 \mathrm{~d} \\
\text { precipitation }\end{array}$ & $\begin{array}{c}\text { Mean seasonal } \\
\text { maxima of } 5 \mathrm{~d} \\
\text { precipitation }\end{array}$ & $\begin{array}{l}50 \text {-year return value } \\
\text { of } 1 \mathrm{~d} \text { precipitation }\end{array}$ & $\begin{array}{l}50 \text {-year return value } \\
\text { of } 5 \mathrm{~d} \text { precipitation }\end{array}$ \\
\hline \multirow{3}{*}{ HadRM3 } & HadCM3Q0 & 24.0 & 16.2 & 13.3 & 21.0 & 19.7 \\
\hline & HadCM3Q3 & 10.4 & 7.4 & 5.7 & 20.9 & 27.0 \\
\hline & HadCM3Q16 & 10.5 & 12.1 & 8.3 & 44.6 & 26.1 \\
\hline \multirow{2}{*}{ HIRHAM } & ARPEGE & -2.4 & 3.3 & 1.7 & 8.4 & 11.1 \\
\hline & ECHAM5 & 24.4 & 11.7 & 10.0 & 20.1 & 18.9 \\
\hline CLM & HadCM3Q0 & 24.0 & 12.7 & 13.8 & 25.2 & 27.6 \\
\hline \multirow{4}{*}{ RCA } & $\mathrm{BCM}$ & 14.9 & 6.7 & 3.2 & 10.3 & 9.8 \\
\hline & ECHAM5 & 27.9 & 9.0 & 9.7 & 31.3 & 23.9 \\
\hline & HadCM3Q3 & 8.1 & 7.8 & 8.8 & 14.1 & 15.2 \\
\hline & HadCM3Q16 & 17.0 & 11.8 & 11.2 & 34.0 & 35.2 \\
\hline RACMO & ECHAM5 & 24.5 & 10.0 & 8.0 & 37.3 & 30.9 \\
\hline REMO & ECHAM5 & 16.2 & 8.9 & 8.7 & 28.7 & 23.5 \\
\hline \multicolumn{7}{|c|}{ JJA } \\
\hline $\mathrm{RCM}$ & Driving GCM & $\begin{array}{l}\text { Mean seasonal } \\
\text { precipitation }\end{array}$ & $\begin{array}{c}\text { Mean seasonal } \\
\text { maxima of } 1 \mathrm{~h} \\
\text { precipitation }\end{array}$ & $\begin{array}{c}\text { Mean seasonal } \\
\text { maxima of } 5 \mathrm{~d} \\
\text { precipitation }\end{array}$ & $\begin{array}{l}50 \text {-year return value } \\
\text { of } 1 \mathrm{~h} \text { precipitation }\end{array}$ & $\begin{array}{l}50 \text {-year return value } \\
\text { of } 5 \mathrm{~d} \text { precipitation }\end{array}$ \\
\hline \multirow{3}{*}{ HadRM3 } & HadCM3Q0 & -32.1 & 0.2 & -3.5 & 7.0 & -5.0 \\
\hline & HadCM3Q3 & -43.2 & -16.1 & -17.5 & -5.7 & -8.8 \\
\hline & HadCM3Q16 & -41.1 & -10.1 & -12.4 & -9.1 & 0.7 \\
\hline \multirow{2}{*}{ HIRHAM } & ARPEGE & -34.1 & 5.3 & 1.0 & 31.6 & 4.6 \\
\hline & ECHAM5 & -3.3 & 17.1 & 15.8 & 44.4 & 25.5 \\
\hline CLM & HadCM3Q0 & -35.2 & -2.0 & -6.1 & 5.4 & 5.8 \\
\hline \multirow{4}{*}{ RCA } & $\mathrm{BCM}$ & -9.0 & 12.1 & 3.7 & 19.9 & 12.1 \\
\hline & ECHAM5 & -18.3 & 9.1 & 0.6 & 20.5 & -0.7 \\
\hline & HadCM3Q3 & -11.4 & 4.8 & -4.1 & 29.4 & 20.3 \\
\hline & HadCM3Q16 & -16.0 & 11.2 & 7.8 & 25.2 & 22.2 \\
\hline RACMO & ECHAM5 & -24.5 & 8.2 & -3.4 & 27.4 & 2.3 \\
\hline REMO & ECHAM5 & -20.4 & 5.4 & -2.4 & 33.4 & 7.5 \\
\hline
\end{tabular}

TABLE 4: Ensemble mean and ensemble quantiles (25\% and 75\%; Q25 and Q75, resp.) of relative changes (in \%) in mean seasonal precipitation totals, mean seasonal maxima, and 50-year return values of 1-hour/1-day and 5-day precipitation amounts in the Carpathian Basin between 2070-2099 and 1961-1990.

\begin{tabular}{|c|c|c|c|c|c|}
\hline \multicolumn{6}{|c|}{ DJF } \\
\hline & $\begin{array}{l}\text { Mean seasonal } \\
\text { precipitation }\end{array}$ & $\begin{array}{c}\text { Mean seasonal } \\
\text { maxima of } 1 \mathrm{~d} \\
\text { precipitation }\end{array}$ & $\begin{array}{c}\text { Mean seasonal } \\
\text { maxima of } 5 \mathrm{~d} \\
\text { precipitation }\end{array}$ & $\begin{array}{l}50 \text {-year return value } \\
\text { of } 1 \mathrm{~d} \text { precipitation }\end{array}$ & $\begin{array}{l}50 \text {-year return value } \\
\text { of } 5 \mathrm{~d} \text { precipitation }\end{array}$ \\
\hline Ensemble mean & 16.6 & 9.8 & 8.5 & 24.7 & 22.4 \\
\hline Q25 & 9.0 & 4.1 & 3.1 & 9.5 & 9.2 \\
\hline Q75 & 24.9 & 15.1 & 13.4 & 37.8 & 33.4 \\
\hline \multicolumn{6}{|c|}{ JJA } \\
\hline & $\begin{array}{l}\text { Mean seasonal } \\
\text { precipitation }\end{array}$ & $\begin{array}{c}\text { Mean seasonal } \\
\text { maxima of } 1 \mathrm{~h} \\
\text { precipitation }\end{array}$ & $\begin{array}{c}\text { Mean seasonal } \\
\text { maxima of } 5 \mathrm{~d} \\
\text { precipitation }\end{array}$ & $\begin{array}{l}50 \text {-year return value } \\
\text { of } 1 \mathrm{~h} \text { precipitation }\end{array}$ & $\begin{array}{l}50 \text {-year return value } \\
\text { of } 5 \mathrm{~d} \text { precipitation }\end{array}$ \\
\hline Ensemble mean & -23.4 & 3.8 & -1.7 & 19.1 & 7.2 \\
\hline Q25 & -36.1 & -4.6 & -10.1 & -1.4 & -9.4 \\
\hline Q75 & -12.4 & 13.1 & 6.3 & 38.7 & 21.5 \\
\hline
\end{tabular}


negative (Table 3 ). These negative values are mostly related to model HadRM3. Individual RCMs show enhanced variability in the spatial distribution of increases and decreases, particularly for the $5 \mathrm{~d}$ precipitation quantiles (Figure 2).

The maps of the ensemble statistics (Figure 3) further demonstrate the low degree of consistency among the RCMs in precipitation extremes in summer: while negative changes prevail on the maps of Q25, the maps of Q75 show uniformly positive changes in the entire region. There is a lesser degree of consistency among the RCMs when considering the sign of the changes on the maps of the ensemble means and particularly so for multiday extremes: while, in the case of $1 \mathrm{~h}$ precipitation, small "+" signs clearly dominate, mostly in the northern and western parts of the area, for the longer duration $(5 \mathrm{~d})$, there is only one larger contiguous region (in western Ukraine and surrounding area) where at least 8 of the 12 RCMs agree on the sign of the projected change.

\section{Discussion}

4.1. Differences within the Carpathian Basin. Even though the target region is relatively small from the global point of view, one may observe regional differences in the projected changes of precipitation characteristics, particularly when comparing two opposite corners of the Carpathian Basin, the northwestern (NW) versus southeastern (SE) parts. The former covers the easternmost part of the Czech Republic, southern Poland, and northwestern parts of Slovakia, while the latter is located in southeastern Romania, relatively close to the delta of the Danube River at the Black Sea.

There are virtually no differences between the two subregions when examining precipitation statistics during winter: judged on the basis of the ensemble mean, all statistics are projected to increase, regardless of the aggregation time. Slight differences only appear in the magnitude of this change; for instance, less wet winters are projected in the SE compared to the NW. In the case of winter maxima, lower magnitudes of positive changes in Romania may be related to the effect of the Carpathian mountain range. The agreement between the individual RCMs is reasonably good, with the exception of the area of the highest elevations of the Carpathians in Romania (cf. Figure 1).

The summer season, however, yields a different picture for the two subregions. The same sign of change appears for two statistics only: mean summer precipitation is projected to decrease, with greater tendency to drier summers in the SE compared to the NW, and short-term (hourly) extremes are projected to increase in both subregions. Nevertheless, for the rest of the statistics (extremes of $5 \mathrm{~d}$ precipitation and seasonal maxima of both short-term and multiday aggregations), the two subregions behave differently. A kind of diagonal gradient from the NW to the SE is found (Figure 3), represented by decreasing values of the projected change. This means that if increases dominate in the NW, indifferent changes or decreases appear in the SE. Such a diagonal gradient may be recognized not only for the ensemble means but also for the ensemble quantiles (Figure 3).

The differences in projected changes between the NW and SE subregions point to the fact that Central Europe represents a transition zone between different parts of the European continent. The SE part of the Carpathian Basin, where continental and Mediterranean influences dominate, is more vulnerable to drying in summer and less prone to increases in precipitation extremes, while in the NW region, where Atlantic influences play more important role, there is a stronger tendency to increases in extremes and a weaker tendency to overall drying in summer in a warmer climate.

4.2. Dependence on Driving GCM Data. Figure 4 shows that the projected changes in precipitation characteristics depend also on the driving GCM data. Summer drying (declines in mean seasonal precipitation) is most pronounced in RCMs driven by HadCM3 while its magnitude is smaller in the rest of the RCMs (driven by ECHAM5, BCM, or ARPEGE), especially in the northern part of the Carpathian Basin. Analogous differences are found for precipitation extremes in summer: while RCMs driven by HadCM3 project decreases in mean summer maxima and spatially incoherent changes in 50-year return values increases clearly prevail in the rest of the RCMs, particularly for short-term $(1 \mathrm{~h})$ extremes.

The differences between RCMs driven by HadCM 3 and ECHAM5 are smaller in winter when these RCM simulations tend to agree on rather uniform positive changes in all characteristics across the region (Figure 4). However, the other two RCM simulations driven by BCM and ARPEGE project much smaller increases, which is also reported in Table 3 for spatial averages (smallest increases of winter precipitation maxima in the whole set of the $12 \mathrm{RCMs}$ ). This suggests that the overall picture of relatively large and uniform changes to wetter conditions in winter may be somewhat biased by the driving data: if more simulations with BCM and ARPEGE (and possibly other GCMs) were available, the overall ensemble mean picture could change. This also points to the importance of having the RCM-GCM matrix as complete as possible in climate change studies.

Note that, in most of the RCMs in summer, the spatially averaged relative changes for the short duration $(1 \mathrm{~h})$ rainfall are more pronounced than for the longer ( $5 \mathrm{~d}$ ) durations; this is particularly true for both HIRHAM simulations and are rather generally valid for the RCMs driven by ECHAM5 (Table 2). Since multiday extremes of precipitation are more closely associated with typical synoptic-scale circulation patterns than hourly extremes, the difference between shortterm and longer durations may be related to projected declines in frequency of these circulation patterns in a warmer climate. The topic of links between circulation patterns conducive to precipitation extremes and their changes in a future climate is an important one and deserves further investigation.

Another interesting feature is that results for a single RCM for which runs with multiple GCMs were available (i.e., HadRM and RCA) are rather similar in summer and depend a little on the driving GCM, particularly in comparison to winter (Table 3). This suggests that the role of boundary conditions taken from GCMs is relatively minor while small-scale processes and their parameterizations in RCMs are much more important for simulated precipitation characteristics in summer. 

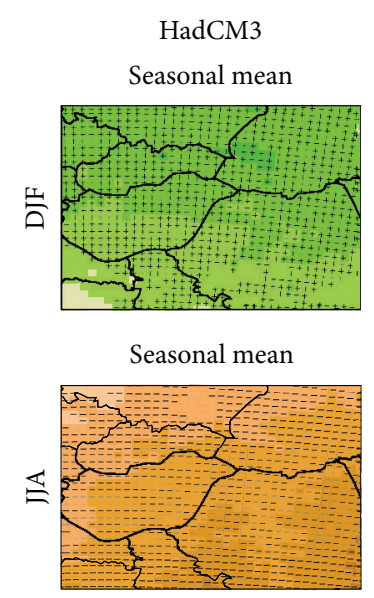

ECHAM5
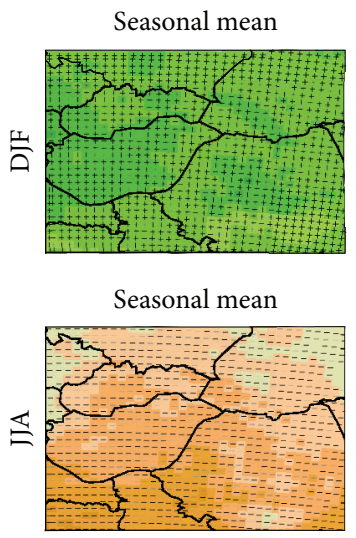

/Seasonal maxima

$1 \mathrm{~d}$

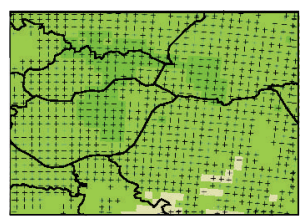

$1 \mathrm{~h}$

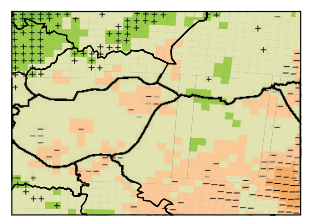

$5 \mathrm{~d}$

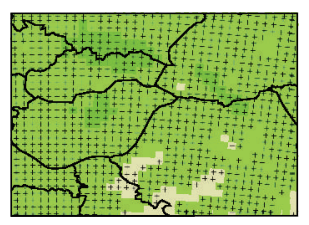

$5 \mathrm{~d}$

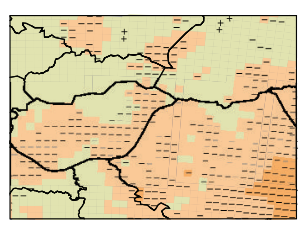

150-year return values

$1 d$

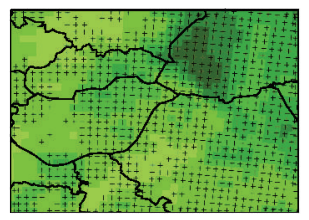

$1 \mathrm{~h}$

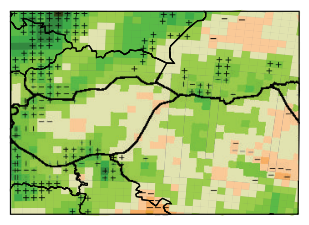

$5 d$

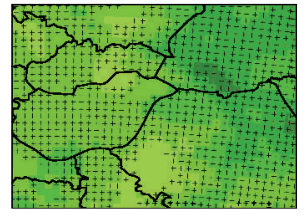

$5 d$

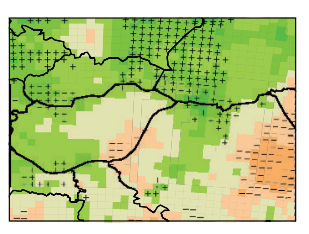

2070-2099

(\%)

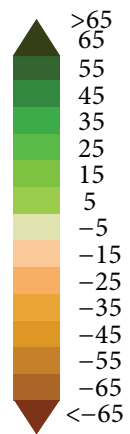

/Seasonal maxima

$1 d$

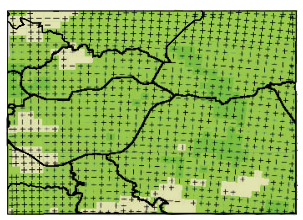

$1 \mathrm{~h}$

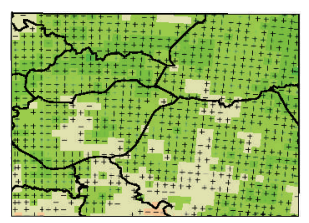

$5 d$

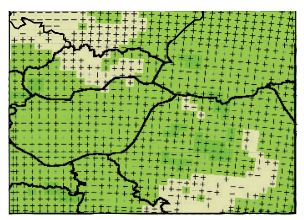

$5 \mathrm{~d}$

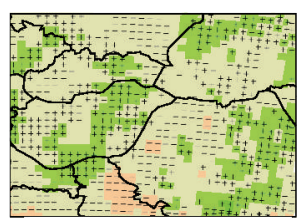

/50-year return values

$1 \mathrm{~d}$

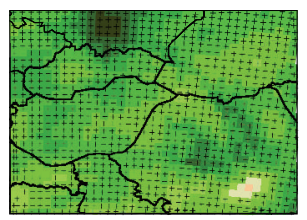

$1 \mathrm{~h}$

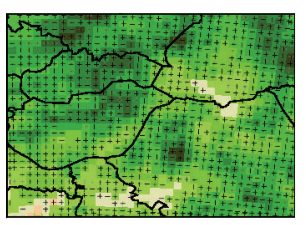

$5 d$

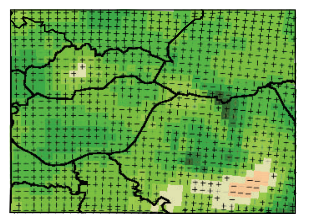

$5 d$

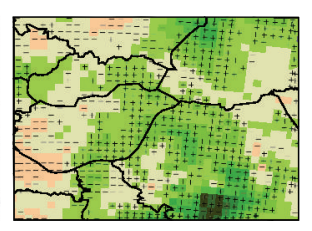

2070-2099

(\%)

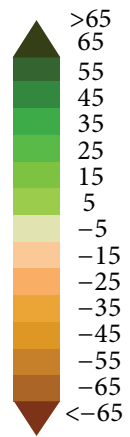

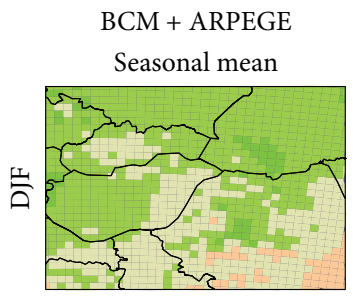

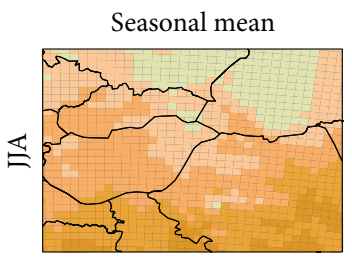

/Seasonal maxima

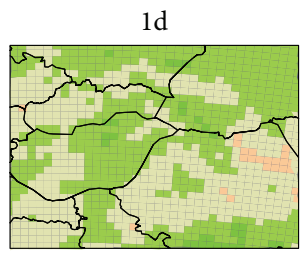

$1 \mathrm{~h}$

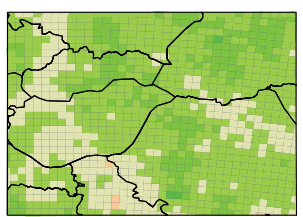

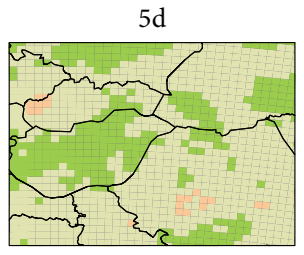

$5 \mathrm{~d}$

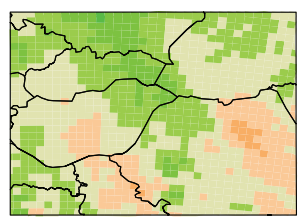

150-year return values

$1 \mathrm{~d}$

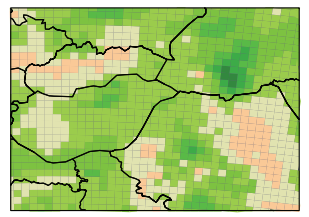

$1 \mathrm{~h}$

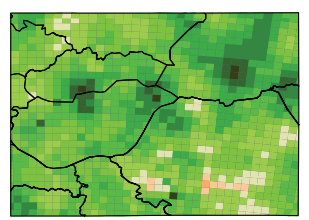

$5 \mathrm{~d}$

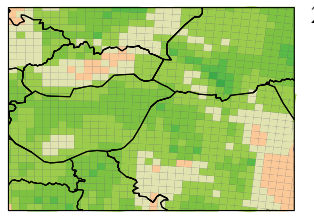

$5 d$

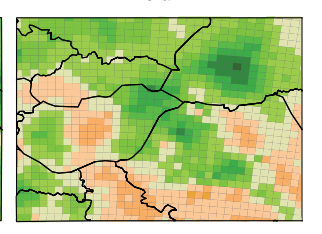

2070-2099

(\%)

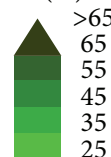

65
55

55
45

25

15

5
-5

$-15$

$-25$

$-35$

$-45$

$-55$

-65
$<-65$

FIGURE 4: Ensemble mean of the projected relative changes (in \%) for the late 21st century (2070-2099) in comparison with the control period (1961-1990), for different driving GCMs: 6 RCMs driven by HadCM3 (top), 4 RCMs driven by ECHAM5 (middle), and 2 RCMs driven by $\mathrm{BCM}$ and ARPEGE (bottom). Same variables as in the case of the two previous figures are displayed, that is, the mean seasonal precipitation, mean seasonal maxima of 1-hour/1-day and 5-day precipitation, and 50-year return values of 1-hour/1-day and 5-day precipitation assessed by the pooling (ROI) approach. Signs " + /-" in the case of HadCM3 (ECHAM5) ensemble indicate grid boxes where at least 5 (3) of the 6 (4) RCMs agree on the sign of change for the given precipitation characteristic. For further details and explanation, see text. 
4.3. Comparison with Other Studies. The results presented in the previous chapters are in good agreement with other studies evaluating projected changes in precipitation characteristics in RCMs, regardless of whether they deal with the whole European continent or focus on a particular region or country. This is not surprising given the fact that the majority of the recent studies were based on outputs of one or more RCMs that were also included in the ensemble from the PRUDENCE [52] or ENSEMBLES [25] projects.

The coherence of these studies is particularly high for mean annual (or seasonal) precipitation, which is most often examined in the context of climate change studies. By the end of the 21st century, wetter winters are projected throughout the European continent, while, in summer, the projected change is regionally differentiated, with wetter (drier) summers in Northern (Southern) Europe (e.g., [10, $11,53])$. Based on an ensemble of 16 global climate models, similar conclusions were formulated for the Carpathian Basin by Bartholy and Pongrácz [8]: mean monthly precipitation amounts are very likely to increase (decrease) in winter and spring (summer and autumn), with smaller changes in the transition seasons.

Beniston et al. [12] reported that winter extremes (characterized by return levels of maximum 5-day precipitation) are likely to increase in Central and Northern Europe while decreases are expected in the south, and the results did not particularly depend on the parameterization of the RCMs used. On the other hand, projected increases in summer extremes (as measured by the return values of the maximum 1-day precipitation) were found over parts of Central and Eastern Europe in spite of the decrease in the mean seasonal precipitation; however, different RCMs showed a smaller degree of agreement in both the sign and the magnitude of the change. In a more recent study, Rajczak et al. [11] arrived at similar conclusions. Winter extremes (supported by strong model agreement) are projected to intensify across most areas of Central Europe. For summer extremes, the model agreement is weak, and Central Europe acts as a transition zone between the north (increased return values) and the south, mainly the Mediterranean (decreased return values). Both regional patterns of the changes in precipitation extremes and the variability among the RCMs as a consequence of the parameterization of the rainfall-generating processes in the RCMs were confirmed in our study by ensemble means and variability among individual RCMs (Figure 3).

Only a small number of studies examined changes in precipitation extremes in the Carpathian Basin in a more focused regional scope. Kržič et al. [7] studied changes in temperature and precipitation extremes in Serbia, however, based on a single RCM only. They concluded that the number of heavy rain days (measured as the number of days per year with daily precipitation exceeding $10 \mathrm{~mm}$ ) will increase significantly during winter in the whole country. Similar indices were analyzed by Bartholy et al. [6] for Hungary. They found that the number of days with higher daily precipitation amounts (10 or $20 \mathrm{~mm}$ ) tended to increase by the end of the 21st century, for all seasons except summer. Rajczak et al. [11] categorized rainfall statistics into three classes: basic, intense, and extreme diagnostics. From this point of view, precipitation indices adopted in $[6,7]$ and seasonal maxima of precipitation analyzed in our study can be considered intense diagnostics. As such, they show a similar behavior.

Although Kyselý et al. [15] concentrated on a different region (Central Europe with the Czech Republic in the main focus), their study is particularly worth comparison since they evaluated projected changes in precipitation extremes by means of a similar methodology. They reported (i) widespread increases both in precipitation extremes and in seasonal totals in winter, (ii) weaker and spatially less coherent increases in precipitation extremes in summer, accompanied by a general decrease in seasonal totals, and (iii) larger increases in summer extremes in western parts of their target region compared to the eastern parts. The present study confirms these findings in a larger neighboring region, except for the fact that the contrast in the magnitude of the projected changes is expressed primarily along the NW-SE diagonal across the Carpathian Basin.

4.4. Hydrological Implications. The main climatic drivers controlling water resources are precipitation and potential evaporation. Therefore, the issue of climate change impacts on hydrological processes is important, especially in relation to changes in extremes including both floods and droughts. Possible changes in runoff regime due to climate change are currently one of the main sources of uncertainty in flood protection and the long-term planning of water resources. Floods in Central and Southeastern Europe caused deaths and widespread property damage across many countries recently [4], and such events are likely to increase in Europe for several reasons, including climate change, according to recent assessments from the European Environment Agency (EEA).

Detected trends in runoff are generally consistent with observed regional changes in precipitation and air temperature. Due to limited evidence there is low confidence that climate change has affected the frequency and magnitude of floods at the global scale [54], but recent detection of trends in extreme precipitation and discharges in river basins implies greater risks of flooding at the regional scale. More locations show increases in heavy precipitation and flood damage costs worldwide have been increasing since the 1970s [55]. Hattermann et al. [56] identified parallel trends in precipitation extremes and flooding in Germany.

The impacts of climate change on hydrological processes are often estimated by hydrological models to develop scenarios that apply projected changes in climate characteristics derived from outputs of GCMs or RCMs. Most hydrological studies applied a small number of climate scenarios but recently an increasing number of studies have used larger ensembles of regional or global models (e.g., [57-59]). Since large differences between projections from individual climate models exist, as shown also in the present study, this is an important step forward in characterizing uncertainty. Some studies also express combined results from multiple climate projections and different emission scenarios by probability distributions of future impacts.

Dankers and Feyen [57] examined future changes in flood risk on the basis of a combination of different GCMs, RCMs, 
and emission scenarios. They found that although on the level of particular catchments significant differences in projections of extreme discharges may appear, at the continental scale, the results show similar patterns. This is illustrated by the example of NE Europe where flood hazards tend to decrease, and this fact is largely influenced by the balance between the reduction in the length of the snow season and the increase in winter precipitation (see also [60]). In this context, Dankers and Feyen [57] also discuss mountain areas of Europe such as the Alps and the Carpathians, but with no clear conclusions (" $[\cdots]$ here the situation is more complicated as extreme orographic rainfall events may play role as well," [57], p. 14).

Future changes in flood hazards are mostly expressed in terms of the peak discharge corresponding to the return period of 100 years. Nevertheless, estimates of the 100year flood, although necessary in engineering hydrology and infrastructure design, cannot reveal further information on the spatial and/or temporal scale of floods. To our knowledge, there are no comprehensive studies focusing on future changes in flood hazards related to different types of floods, for example, flash floods versus large-scale floods. This is an important issue and results of our study show that climatological and hydrological extremes need to be examined on a multitude of time scales. Different behavior of precipitation extremes on different aggregation levels is projected by the RCMs, which implies that future changes of flood risk are likely to depend on both spatial and temporal scales considered.

\section{Conclusions}

In winter, all examined characteristics of precipitation (seasonal totals, mean seasonal maxima, and 50-year return values for both daily and multiday aggregations) show similar patterns of projected increases in the Carpathian Basin for the late 21 st century compared to the recent climate. Differences only appear in the magnitude: the most marked changes, by $22-25 \%$ if averaged over the RCMs and the study area, are associated with the 50-year return values of precipitation. Individual RCMs generally show a high degree of agreement in the magnitude and the sign of the changes, with relatively low spread among the models. No single RCM projects declines of precipitation extremes in winter if averaged over the Carpathian Basin.

In summer, by contrast, drying is projected for seasonal totals in all RCMs. For mean seasonal maxima of shortterm (hourly) and 5-day amounts, however, there is no clear pattern of prevailing increases or declines, and, for high quantiles (high-impact events, represented by 50 -year return values in the present study), increases clearly prevail. They are larger for short-term extremes that are more directly related to convective activity than multiday extremes. This suggests that the frequency of flash floods may increase more than the occurrence of large-scale floods in a warmer climate. The within-ensemble variability (and associated uncertainty) is, nevertheless, much larger in summer than in winter.

As far as we know, no climate change studies exist in relation to precipitation extremes of the subdaily scale which are specifically targeted to Central and Southeastern Europe, although this is a region where flash floods often occur in warm half year and cause major damage [49]. Since flash floods are usually related to severe convective phenomena (e.g., $[1,26,61])$, subdaily amounts are probably better proxies for such events than more often examined daily amounts. On the other hand, heavy 5-day precipitation is considered a measure of the occurrence of large-scale floods in climate model studies (e.g., [17, 35-39]), and its possible changes in a warmer climate are widely studied. We show that there are important differences between scenarios of short-term (1-hour) and multiday (5-day) rainfall extremes in summer, so future studies should pay larger attention to the subdaily precipitation extremes as well. The present analysis suggests that if climate change effects on precipitation extremes are assessed from daily and multiday amounts only, possible increases due to climate change and associated risks might be underestimated.

\section{Conflict of Interests}

The authors declare that there is no conflict of interests regarding the publication of this paper.

\section{Acknowledgments}

The RCM data were obtained from the ENSEMBLES project database funded within the EU-FP6, Contract no. 505539. The study was supported by the Czech Science Foundation under Project 14-18675S and by the Slovak Research and Development Agency under Contract no. APVV-0303-11.

\section{References}

[1] L. Marchi, M. Borga, E. Preciso, and E. Gaume, "Characterisation of selected extreme flash floods in Europe and implications for flood risk management," Journal of Hydrology, vol. 394, no. 1-2, pp. 118-133, 2010.

[2] J. L. Catto and S. Pfahl, "The importance of fronts for extreme precipitation," Journal of Geophysical Research: Atmosphere, vol. 118, pp. 10,791-10,801, 2013.

[3] G. Blöschl, T. Nester, J. Komma, J. Parajka, and R. A. P. Perdigão, "The June 2013 flood in the Upper Danube basin, and comparisons with the 2002, 1954 and 1899 floods," Hydrology and Earth System Sciences, vol. 10, pp. 9533-9573, 2013.

[4] J. Kyselý, L. Gaál, J. Picek, and M. Schindler, "Return periods of the August 2010 heavy precipitation in northern Bohemia (Czech Republic) in the present climate and under climate change," Journal of Water and Climate Change, vol. 4, no. 3, pp. 265-286, 2010.

[5] IPCC, Climate Change: The Physical Science Basis. Contribution of Working Group I to the IPCC 4th Assessment Report, Cambridge University Press, Cambridge, UK, 2007.

[6] J. Bartholy, L. Bozó, and L. Haszpra, Eds., Klímaváltozás 2011Klímaszcenáriók a Kárpát-Medence Térségére (Climate Change 2011-Climate Scenarios for the Area of the Carpathian Basin), Hungarian Academy of Sciences; Department of Meteorology of Eötvös Loránd University, Budapest, Hungary, 2011, (Hungarian). 
[7] A. Kržič, I. Tošić, V. Djurdjević, K. Veljović, and B. Rajković, "Changes in climate indices for Serbia according to the SRESA1B and SRES-A2 scenarios," Climate Research, vol. 49, no. 1, pp. 73-86, 2011.

[8] J. Bartholy and R. Pongrácz, "Analysis of precipitation conditions for the Carpathian Basin based on extreme indices in the 20th century and climate simulations for 2050 and 2100," Physics and Chemistry of the Earth, vol. 35, no. 1-2, pp. 43-51, 2010.

[9] R. Pongrácz, J. Bartholy, and E. Miklós, "Analysis of projected climate change for Hungary using ENSEMBLES simulations," Applied Ecology and Environmental Research, vol. 9, no. 4, pp. 387-398, 2011.

[10] G. Nikulin, E. Kjellström, U. Hansson, G. Strandberg, and A. Ullerstig, "Evaluation and future projections of temperature, precipitation and wind extremes over Europe in an ensemble of regional climate simulations," Tellus A, vol. 63, no. 1, pp. 41-55, 2011.

[11] J. Rajczak, P. Pall, and C. Schär, "Projections of extreme precipitation events in regional climate simulations for Europe and the Alpine Region," Journal of Geophysical Research D: Atmospheres, vol. 118, no. 9, pp. 3610-3626, 2013.

[12] M. Beniston, D. B. Stephenson, O. B. Christensen et al., "Future extreme events in European climate: an exploration of regional climate model projections," Climatic Change, vol. 81, no. 1, pp. 71-95, 2007.

[13] J. Kyselý and R. Beranová, "Climate-change effects on extreme precipitation in central Europe: uncertainties of scenarios based on regional climate models," Theoretical and Applied Climatology, vol. 95, no. 3-4, pp. 361-374, 2009.

[14] H. Feldmann, G. Schädler, H. Panitz, and C. Kottmeier, "Near future changes of extreme precipitation over complex terrain in Central Europe derived from high resolution RCM ensemble simulations," International Journal of Climatology, vol. 33, no. 8, pp. 1964-1977, 2013.

[15] J. Kyselý, L. Gaál, R. Beranová, and E. Plavcová, “Climate change scenarios of precipitation extremes in Central Europe from ENSEMBLES regional climate models," Theoretical and Applied Climatology, vol. 104, pp. 529-542, 2011.

[16] H. J. Fowler, M. Ekström, S. Blenkinsop, and A. P. Smith, "Estimating change in extreme European precipitation using a multimodel ensemble," Journal of Geophysical Research D: Atmospheres, vol. 112, no. 18, Article ID D18104, 2007.

[17] S. C. van Pelt, J. J. Beersma, T. A. Buishand, B. J. J. M. van den Hurk, and P. Kabat, "Future changes in extreme precipitation in the rhine basin based on global and regional climate model simulations," Hydrology and Earth System Sciences, vol. 16, no. 12, pp. 4517-4530, 2012.

[18] A. N. Larsen, I. B. Gregersen, O. B. Christensen, J. J. Linde, and P. S. Mikkelsen, "Future development in extreme one-hour precipitation over Europe due to climate change," in Proceedings of the 11th International Conference on Urban Drainage, University of Sheffield, Edinburgh, UK, September 2008.

[19] G. Lenderink and E. Van Meijgaard, "Increase in hourly precipitation extremes beyond expectations from temperature changes," Nature Geoscience, vol. 1, no. 8, pp. 511-514, 2008.

[20] J. Kyselý, S. Beguería, R. Beranová, L. Gaál, and J. I. López -Moreno, "Different patterns of climate change scenarios for short-term and multi-day precipitation extremes in the Mediterranean," Global and Planetary Change, vol. 98-99, pp. 63-72, 2012.
[21] M. Hanel and T. A. Buishand, "On the value of hourly precipitation extremes in regional climate model simulations," Journal of Hydrology, vol. 393, no. 3-4, pp. 265-273, 2010.

[22] P. Frich, L. V. Alexander, P. Della-Marta et al., "Observed coherent changes in climatic extremes during the second half of the twentieth century," Climate Research, vol. 19, no. 3, pp. 193-212, 2002.

[23] R. Pongrácz, J. Bartholy, and P. Szabó, "Analysis of expected change of extreme climate indices in the Carpathian basin by 2071-2100," in Proceeding of the 89th AMS Annual Meeting/21st Conference on Climate Variability and Change, p. 5, Phoenix, Ariz, USA, January 2009.

[24] D. H. Burn, "Evaluation of regional flood frequency analysis with a region of influence approach," Water Resources Research, vol. 26, no. 10, pp. 2257-2265, 1990.

[25] P. van der Linden and J. F. B. Mitchell, Eds., ENSEMBLES: Climate Change and its Impacts: Summary of Research and Results from the ENSEMBLES Project, Met Office Hadley Centre, Exeter, UK, 2009.

[26] E. Roeckner, G. Bäuml, L. Bonaventura et al., “The atmospheric general circulation model ECHAM5-part I: model description," Tech. Rep. 349, Max-Planck-Institut für Meteorologie, Hamburg, Germany, 2003.

[27] T. Furevik, M. Bentsen, H. Drange, I. K. T. Kindem, N. G. Kvamstø, and A. Sorteberg, "Description and evaluation of the bergen climate model: ARPEGE coupled with MICOM," Climate Dynamics, vol. 21, no. 1, pp. 27-51, 2003.

[28] M. Déqué, C. Dreveton, A. Braun, and D. Cariolle, "The ARPEGE/IFS atmosphere model: a contribution to the French community climate modelling," Climate Dynamics, vol. 10, no. 4-5, pp. 249-266, 1994.

[29] T. C. Johns, J. M. Gregory, W. J. Ingram et al., "Anthropogenic climate change for 1860 to 2100 simulated with the HadCM3 model under updated emissions scenarios," Climate Dynamics, vol. 20, no. 6, pp. 583-612, 2003.

[30] S. Herrera, L. Fita, J. Fernández, and J. M. Gutiérrez, "Evaluation of the mean and extreme precipitation regimes from the ENSEMBLES regional climate multimodel simulations over Spain," Journal of Geophysical Research D: Atmospheres, vol. 115, no. $21,2010$.

[31] E. Kostopoulou, C. Giannakopoulos, M. Hatzaki, and K. Tziotziou, "Climate extremes in the NE Mediterranean: assessing the E-OBS dataset and regional climate simulations," Climate Research, vol. 54, no. 3, pp. 249-270, 2012.

[32] R. Deidda, M. Marrocu, G. Caroletti et al., "Regional climate models' performance in representing precipitation and temperature over selected Mediterranean areas," Hydrology and Earth System Sciences, vol. 17, pp. 5041-5059, 2013.

[33] E. Plavcová, J. Kyselý, and P. Štěpánek, "Links between circulation types and precipitation in Central Europe in the observed data and regional climate model simulations," International Journal of Climatology, vol. 34, no. 9, pp. 2885-2898, 2014.

[34] V. Ruiz-Villanueva, M. Borga, D. Zoccatelli, L. Marchi, E. Gaume, and U. Ehret, "Extreme flood response to shortduration convective rainfall in South-West Germany," Hydrology and Earth System Sciences, vol. 16, no. 5, pp. 1543-1559, 2012.

[35] X. Gao, J. S. Pal, and F. Giorgi, "Projected changes in mean and extreme precipitation over the Mediterranean region from a high resolution double nested RCM simulation," Geophysical Research Letters, vol. 33, no. 3, Article ID L03706, 2006.

[36] C. Boroneant, G. Plaut, F. Giorgi, and X. Bi, "Extreme precipitation over the Maritime Alps and associated weather regimes 
simulated by a regional climate model: present-day and future climate scenarios," Theoretical and Applied Climatology, vol. 86, pp. 81-99, 2006.

[37] M. Hanel and T. A. Buishand, "Analysis of precipitation extremes in an ensemble of transient regional climate model simulations for the Rhine basin," Climate Dynamics, vol. 36, no. 5-6, pp. 1135-1153, 2011.

[38] J. Sillmann, V. V. Kharin, F. W. Zwiers, X. Zhang, and D. Bronaugh, "Climate extremes indices in the CMIP5 multimodel ensemble: Part 2. Future climate projections," Journal of Geophysical Research D: Atmospheres, vol. 118, no. 6, pp. 2473-2493, 2013.

[39] R. V. Haren, G. J. V. Oldenborgh, G. Lenderink, and W. Hazeleger, "Evaluation of modeled changes in extreme precipitation in Europe and the Rhine basin," Environmental Research Letters, vol. 8, no. 1, Article ID 014053, 2013.

[40] Z. Rulfová and J. Kyselý, "Disaggregating convective and stratiform precipitation from station weather data," Atmospheric Research, vol. 134, pp. 100-115, 2013.

[41] M. Ekström, H. J. Fowler, C. G. Kilsby, and P. D. Jones, "New estimates of future changes in extreme rainfall across the UK using regional climate model integrations. 2. Future estimates and use in impact studies," Journal of Hydrology, vol. 300, no. 1-4, pp. 234-251, 2005.

[42] J. R. M. Hosking and J. R. Wallis, Regional Frequency Analysis: An Approach Based on L-moments, Cambridge University Press, Cambridge, UK, 1997.

[43] A. Viglione, F. Laio, and P. Claps, "A comparison of homogeneity tests for regional frequency analysis," Water Resources Research, vol. 43, no. 3, Article ID W03428, 2007.

[44] L. Lu and J. R. Stedinger, "Sampling variance of normalized GEV/PWM quantile estimators and a regional homogeneity test," Journal of Hydrology, vol. 138, no. 1-2, pp. 223-245, 1992.

[45] D. W. Reed, D. Jakob, A. J. Robinson, D. A. Faulkner, and E. J. Stewart, "Regional frequency analysis: a new vocabulary," in Proceedings of the Symposium Hydrological Extremes: Understanding, Predicting, Mitigating (IUGG'99), vol. no. 255, pp. 237243, IAHS Publications, Birmingham, UK, 1999.

[46] A. Castellarin, D. H. Burn, and A. Brath, "Assessing the effectiveness of hydrological similarity measures for flood frequency analysis," Journal of Hydrology, vol. 241, no. 3-4, pp. 270-285, 2001.

[47] L. Gaál, J. Kyselý, and J. Szolgay, "Region-of-influence approach to a frequency analysis of heavy precipitation in Slovakia," Hydrology and Earth System Sciences, vol. 12, no. 3, pp. 825-839, 2008.

[48] L. Gaál and J. Kyselý, "Comparison of region-of-influence methods for estimating high quantiles of precipitation in a dense dataset in the Czech Republic," Hydrology and Earth System Sciences, vol. 13, no. 11, pp. 2203-2219, 2009.

[49] J. Kyselý, L. Gaál, and J. Picek, "Comparison of regional and at-site approaches to modelling probabilities of heavy precipitation," International Journal of Climatology, vol. 31, no. 10, pp. 1457-1472, 2011.

[50] S. Coles, An Introduction to Statistical Modeling of Extreme Values, Springer, London, UK, 2001.

[51] A. R. Rao and K. H. Hamed, Flood Frequency Analysis, CRC Press, Boca Raton, Fla, USA, 1999.

[52] J. H. Christensen and O. B. Christensen, "A summary of the PRUDENCE model projections of changes in European climate by the end of this century," Climatic Change, vol. 81, no. 1, pp. 730, 2007.
[53] Z. W. Kundzewicz, M. Radziejewski, and I. Pińskwar, "Precipitation extremes in the changing climate of Europe," Climate Research, vol. 31, no. 1, pp. 51-58, 2006.

[54] Z. W. Kundzewicz, S. Kanae, S. I. Seneviratne et al., "Flood risk and climate change: global and regional perspectives," Hydrological Sciences Journal, vol. 59, no. 1, pp. 1-28, 2013.

[55] J. Handmer, Y. Honda, Z. W. Kundzewicz et al., "Changes in impacts of climate extremes: human systems and ecosystems," in Managing the Risks of Extreme Events and Disasters to Advance Climate Change Adaptation, C. B. Field, V. Barros, T. F. Stocker, and etal, Eds., pp. 231-290, Cambridge University Press, Cambridge, UK, A Special Report of Working Groups I and II of the Intergovernmental Panel on Climate Change (IPCC), 2012.

[56] F. F. Hattermann, Z. W. Kundzewicz, S. Huang et al., "Flood risk from a holistic perspective-observed changes in Germany," in Changes in Flood Risk in Europe, Z. W. Kundzewicz, Ed., pp. 212237, CRC Press, Wallingford, UK, 2012.

[57] R. Dankers and L. Feyen, "Flood hazard in Europe in an ensemble of regional climate scenarios," Journal of Geophysical Research D: Atmospheres, vol. 114, no. 16, Article ID D16108, 2009.

[58] N. W. Arnell, "Incorporating climate change into water resources planning in England and Wales," Journal of the American Water Resources Association, vol. 47, no. 3, pp. 541549, 2011.

[59] N. W. Arnell and S. N. Gosling, "The impacts of climate change on river flow regimes at the global scale," Journal of Hydrology, vol. 486, pp. 351-364, 2013.

[60] J. C. Adam, A. F. Hamlet, and D. P. Lettenmaier, "Implications of global climate change for snowmelt hydrology in the twentyfirst century," Hydrological Processes, vol. 23, no. 7, pp. 962-972, 2009.

[61] E. Gaume, V. Bain, P. Bernardara et al., "A compilation of data on European flash floods," Journal of Hydrology, vol. 367, no. 1-2, pp. 70-78, 2009.

[62] P. Samuelsson, C. G. Jones, U. Willén et al., "The Rossby Centre regional climate model RCA3: model description and performance," Tellus, vol. 63, no. 1, pp. 4-23, 2011.

[63] R. G. Jones, M. Noguer, D. C. Hassell et al., Generating HighResolution Climate Change Scenarios Using PRECIS, Met Office Hadley Centre, Exeter, UK, 2004.

[64] J. H. Christensen, O. B. Christensen, P. Lopez, E. van Meijgaard, and M. Botzet, "The HIRHAM4 regional atmospheric climate model," Scientific Report 964, DMI, Copenhagen, Denmark, 1996.

[65] E. van Meijgaard, L. H. van Ulft, W. J. van de Berg et al., "The KNMI regional atmospheric climate model RACMO, version 2.1," KNMI Tech Rep 302, Royal Netherlands Meteorological Institute, De Bilt, Netherlands, 2008.

[66] D. Jacob, "A note to the simulation of the annual and interannual variability of the water budget over the Baltic Sea drainage basin," Meteorology and Atmospheric Physics, vol. 77, no. 1-4, pp. 61-73, 2001.

[67] J. Steppeler, G. Doms, U. Schättler et al., "Meso-gamma scale forecasts using the nonhydrostatic model LM," Meteorology and Atmospheric Physics, vol. 82, no. 1-4, pp. 75-96, 2003. 

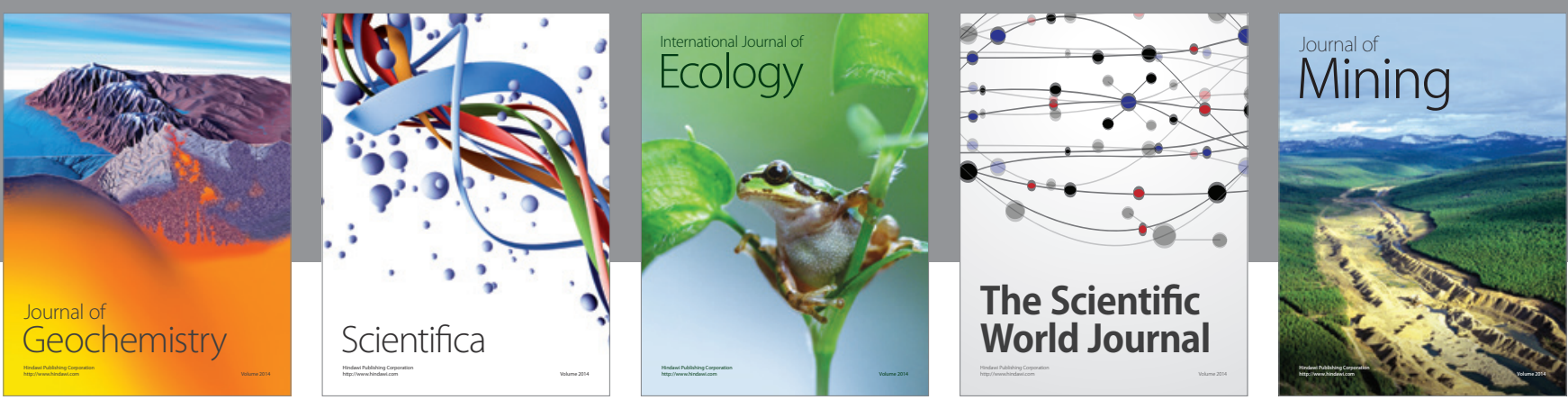

The Scientific World Journal
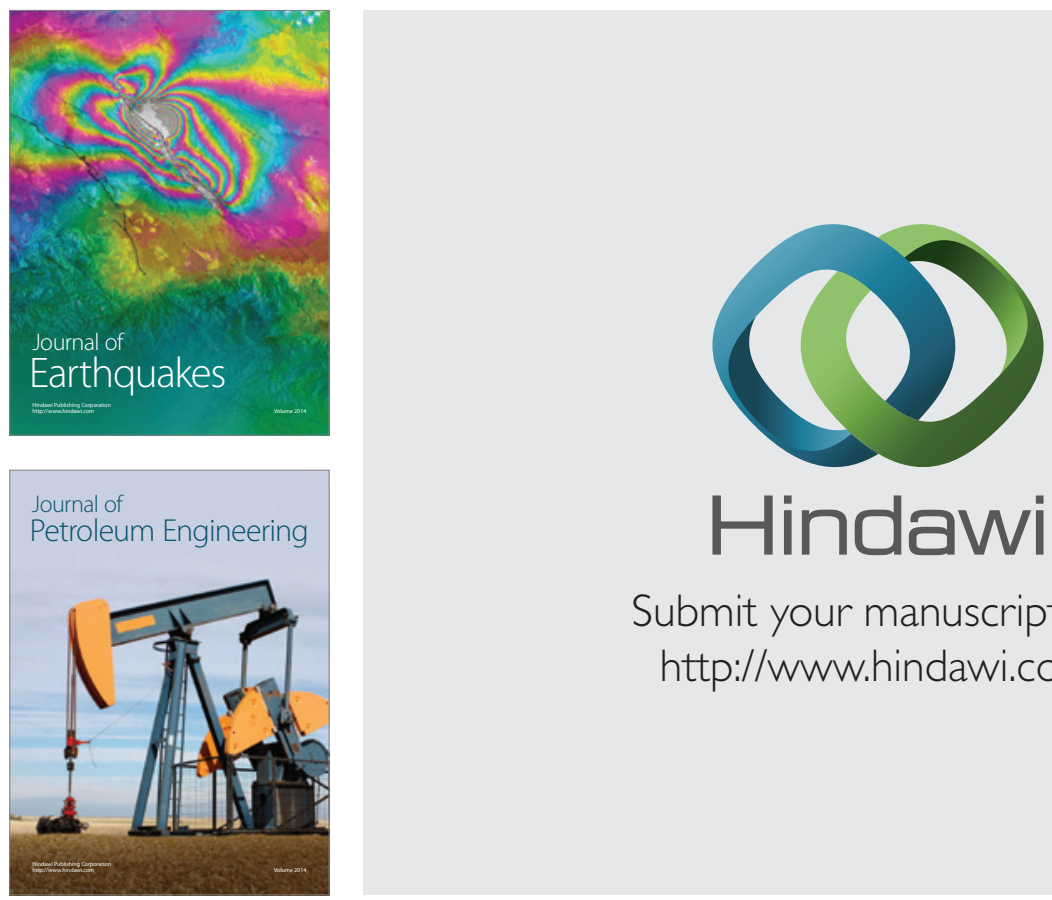

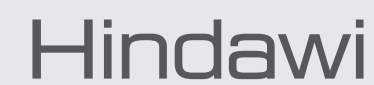

Submit your manuscripts at

http://www.hindawi.com
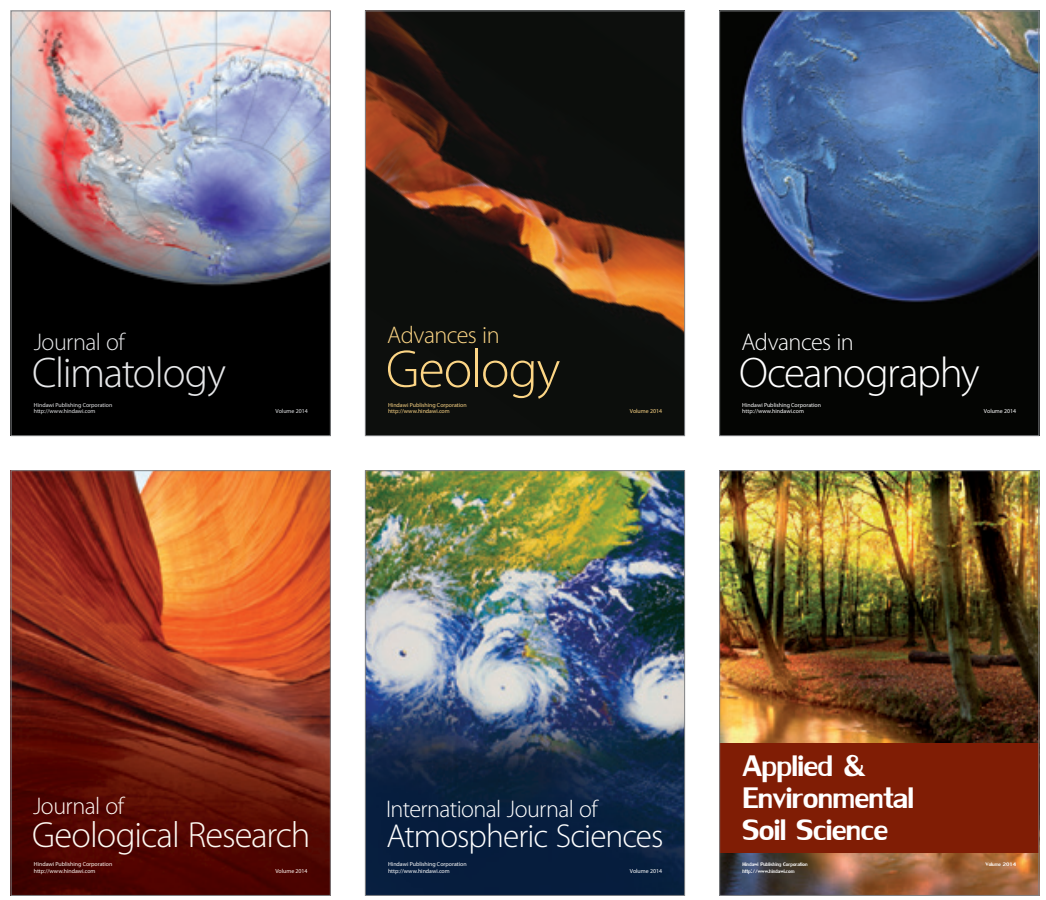
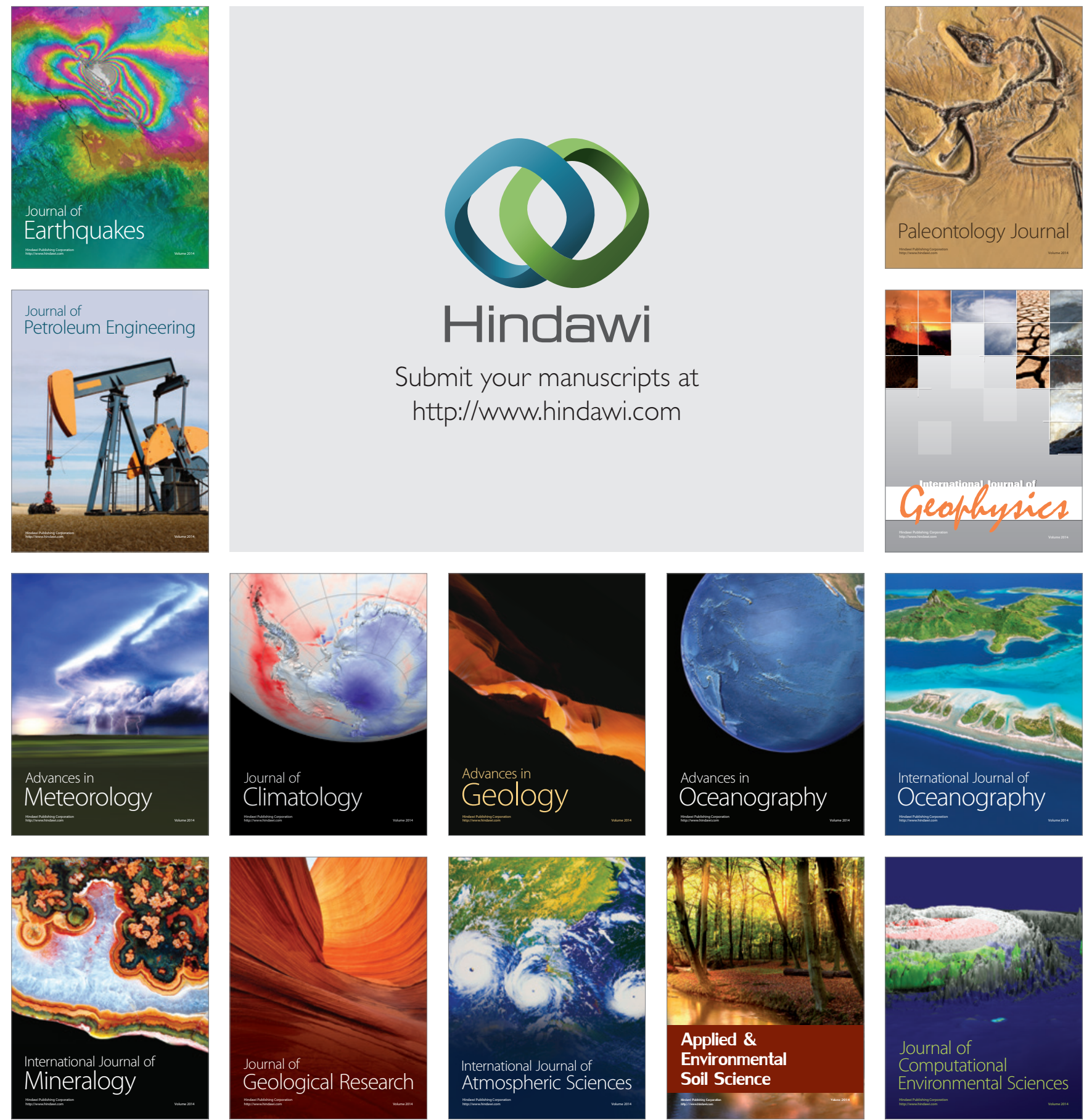